\title{
A VOZ ENLUTADA NA TRAGÉDIA GREGA
}

\section{THE MOURNING VOICE IN THE GREEK TRAGEDY}

\author{
Tiago Sanches Nogueira ${ }^{1}$
}

\begin{abstract}
Resumo: $\mathrm{O}$ artigo propõe reflexão sobre o modo como a tragédia grega inscreveu em seus textos a presença daquilo que chamamos de "voz enlutada". Trata-se da materialização, em uma emissão vocal genérica, da dor de uma perda fundamental que rege a vida do sujeito. Para nós, tal perda está associada àquela que a psicanálise descreve como primeira vivência de satisfação experimentada no laço com o Outro. Para sempre perdida, tal vivência é expressada na tragédia sob a forma da interjeição aîâ̂. Apresentando-se como um desdobramento do advérbio aeí (sempre) derivado de aion (força vital), o grito aîâ̂ parece expressar a dor de um "para sempre" perdido que aos poucos se constitui como o próprio ato de perder. A tentativa de reencontro do objeto, a partir desta perda fundamental, será para sempre representado por Outra coisa.
\end{abstract}

Palavras-Chave: tragédia grega; voz; luto.

Abstract: The article proposes reflection on the way in which Greek tragedy inscribed in its texts the presence of what we call the "mourning voice". It is the materialization, in a generic vocal emission, of the pain of a fundamental loss that governs the subject's life. For us, this loss is associated with what psychoanalysis describes as the first experience of satisfaction experienced in the bond with the Other. Forever lost, such an experience is expressed in the tragedy in the form of the interjection aîai. Presenting itself as an offshoot of the adverb aeí (always) derived from aion (vital force), the cry aîaî seems to express the pain of a lost "forever" that gradually constitutes the very act of losing. The attempt to rediscover the object, based on this fundamental loss, will be forever represented by Something else.

Keywords: greek tragedy; voice; mourning.

\section{CONSIDERAÇÕES INICIAIS}

Durante o ano de 2018 realizamos uma oficina de composição de canções junto a sujeitos afetados por experiências de violência e de desenraizamento ${ }^{2}$. Partindo da constatação de que a experiência musical pode contribuir em termos de tratamento para a clínica do traumático, tínhamos como objetivo transformar em narrativa o impacto da perda da experiência produzida pelo trauma. Sabemos que a noção de experiência em

\footnotetext{
1 Tiago Sanches Nogueira, Psicanalista, Doutor em Psicologia Clínica pela Universidade de São Paulo (USP). Autor do livro "Ensaio sobre um Infinito: Música e Psicanálise"; Músico-criador, autor do Álbum Musical ESGRITOS: ROMANCE DE FORMAÇÃO; Membro do Laboratório de Psicanálise, Sociedade e Política (PSOPOL-USP). Santo André-SP. tiagosanchesnogueira@gmail.com Orcid: https://orcid.org/0000-0002-3750-9834

2 A oficina foi realizada em dois centros de atendimento a refugiados em São Paulo. Nela recebíamos migrantes, solicitantes de refúgio, imigrantes, exilados, deslocados internos, imigrantes econômicos, menores desacompanhados, refugiados ambientais, migrantes regulares, migrantes irregulares, clandestinos, errantes, viajantes, párias, apátridas, imigrantes indocumentados, sem papéis, imigrantes ilegais, devolvidos, retidos, repatriados, reassentados, retornados. Cada um deles carregavam uma história singular que poderia ser compartilhada através das chamadas "canções de si".
} 
psicanálise diz respeito a uma gramática em torno do objeto perdido, da experiência de perda e da perda da experiência (Reis, 2015). Essa formulação, apesar de se aproximar da formulação sobre a experiência como encontro com o objeto faltoso, nos trouxe a novidade de problematizar o luto em diálogo com a dificuldade de nomeação do vivido, exigindo certa recomposição de algo que se perdeu.

A intensa pesquisa musical e teórica para a construção de nosso dispositivo clínico nos levou ao estudo da tragédia grega e, sobretudo, ao modo como o tema do luto e da perda é colocado em cena através da voz falada e cantada. Descobrimos que há na tragédia grega a estrutura de uma dramaturgia que é originariamente musical. O problema das traduções dos textos trágicos impede que as encenações modernas mantenham o justo equilíbrio entre a musicalidade inerente à tragédia e o seu texto escrito. Com o abandono da música, tanto o peso das palavras, quanto a densidade sonora das encenações se perderam. O mais importante aqui é que havia algo na forma de falar ou cantar o texto que remetia ao que Nicole Loraux (1999), importante helenista francesa, chamou de voz enlutada.

A ideia de uma voz enlutada nos remete a Luto e Melancolia (1917[1915]/2011), texto em que Freud nos ensina que o luto é um trabalho principiado pela reação à uma perda que comporta uma vivência dolorosa atribuída à necessidade de abandono de uma posição libidinal (Freud, 1917[1915]/2011). A retirada de investimento do objeto que foi perdido vem acompanhada de sofrimento, justamente pelo fato do "Eu" não abandonar de bom grado a posição da libido. A custa de muito trabalho, as lembranças e expectativas pelas quais a libido se ligava ao objeto são, uma a uma, focalizadas e superinvestidas, realizando nelas o desligamento da libido.

Tal trabalho de desligamento e de reinvestimento da libido costuma ser facilitado por ritos que permitem a designação de signos que dão visibilidade e reconhecimento à perda. Apesar de Freud não mencionar em seu texto a importância dos rituais no luto, ele ressalta o valor da queixa naqueles que apresentam dificuldades para elaboração do luto. Neles, a queixa institui-se como um verdadeiro rito no qual o enlutado pode "dar queixa" (tal como nos referimos ao réu em um processo) de sua perda através de seu prantear.

Foi isso que observamos em nossa pesquisa sobre a tragédia grega. Nela, constatamos a presença de cantos de lamentos que, a nosso ver, parecem dar queixa de algo relacionado àquilo que foi e está perdido para sempre da experiência humana. Poderíamos dizer que em termos psicanalíticos, este algo perdido é justamente a vivência de satisfação impossível de esquecer, esta alguma coisa que, no nível do inconsciente, só uma representação representa (LACAN, 1959- 60/1991, p. 92).

Segundo Garcia-Roza (2009), quando um recém-nascido premido pela fome chora e agita os braços e as pernas, essas respostas motoras são ineficazes para a eliminação do estado de estimulação na fonte corporal. O alívio da tensão só pode ser obtido através de uma ação específica, capaz de eliminar o estado de estimulação na fonte (FREUD, 1905). É exatamente isto que o recém-nascido não é capaz de fazer sem o auxílio de outra pessoa que fornece o alimento (no caso da fome), suprimindo assim a tensão. É a eliminação da tensão decorrente dos estímulos internos que dá lugar ao que Freud denomina vivência de satisfação.

A partir dessa vivência primária de satisfação, estabelece-se uma facilitação (Bahnung), de tal modo que ao se repetir o estado de necessidade, surgirá um impulso psíquico que reinveste a imagem mnêmica do objeto, com a finalidade de reproduzir a satisfação original. A partir da experiência de vivência de satisfação, estabelece-se uma ligação entre a imagem do objeto que proporcionou a satisfação e a imagem do movimento que permitiu a descarga. Com a repetição do estado de necessidade, surge 
imediatamente um impulso psíquico que procurará reinvestir a imagem-lembrança da percepção do objeto, reproduzindo a situação de satisfação original.

Sendo assim, a voz enlutada na tragédia nos remete à queixa sobre o objeto perdido que na constituição do sujeito se desdobra numa dialética entre sujeito e Outro ${ }^{3}$, na qual a própria linguagem recupera aquilo que ela perde por operar (SAFATLE, 2006, p. 126). Se um objeto pode ser pensado como aquilo que está no lugar de representação desta perda, todo objeto perdido recoloca o sujeito na busca do reencontro de uma Coisa que estará para sempre perdida (LACAN, 1959-1960).

\title{
2. A ESTRUTURA DA TRAGÉDIA GREGA
}

A palavra tragédia (tragoidía) é derivada da combinação das palavras gregas trágos (bode) e oide (canção, ode, canto), ou seja, algo como o "canção ou canto dos bodes". A hipótese dos estudiosos acerca desse nome aproxima a tragédia grega de sua origem religiosa e musical. Segundo a filóloga Jacqueline de Romilly (1970), a chegada da primavera era motivo de celebração para os atenienses que realizavam grandes festas urbanas em cultos ao deus Dionísio. Também havia as Dionisíacas Leneanas, festas celebradas no fim de dezembro que tinham como uma de suas atrações o concurso de tragédias.

Em sua Poética (2015), Aristóteles faz referência ao dithýrambos, canto de louvor a Dionísio executado por um coro acompanhado pelo Aulo, do qual a tragédia teria derivado. Segundo Vivès (2010), o dithýrambo era uma cerimônia de invocação realizada pelo chefe de um coro (eksárkhos) que improvisava um canto ao mesmo tempo em que um coro respondia executando danças e evoluções em torno do altar de Dionísio localizado em um ponto central:

\footnotetext{
"O coro trágico se desdobra face ao ator mas igualmente face ao espectador (...) Onde o coro ditirâmbico se mostrava em uma completude tranquilizante, o coro trágico, perdendo um de seus membros, que se torna protagonista, alterando-se e descobrindo uma articulação outra entre voz e fala, e igualmente, entre ilusão e ficção" (VIVĖS, 2019, p. 46, tradução nossa).
}

Jeanmaire (1951) refere que os antigos opunham os cantos triunfais de Apolo às agitações tumultuosas dos dithýrambos. Bromos, um dos possíveis nomes dados a Dionísio, evoca seu aspecto barulhento que, segundo o autor, justificava o fato de a música que o louvava ser tão barulhenta a ponto de dificultar a audição dos poemas que nela estavam contidos.

Jean-Michel Vivès assinala a importância do apontamento de Jeanmaire sobre a dimensão do ruído inarticulado e contínuo nos dithýrambos:

\begin{abstract}
"O ditirambo é barulhento como é o deus para o qual ele se endereça. A fala aqui é inaudível mas esta explosão é, portanto, endereçada e então orientada. Esta selvageria que caracteriza o ditirambo encontra sua origem na comemoração de um sacrifício que implica que os celebrantes tenham alcançado, através das práticas relativas ao culto de Dionísio, um nível de transe que torna possível o ritual omofágico (devoração da carne crua da vítima dilacerada). O ditirambo ritual que começa por uma caça ritual ou um simulacro de caça tumultuosa à uma ou mais vítimas, resulta na formação de uma ronda feroz, geradora de excitação e de êxtase coletivo de onde saiu o "coro
\end{abstract}

\footnotetext{
${ }^{3}$ Para Lacan, o Outro é "o lugar onde a fala se confirma por encontrar a troca dos significantes, os ideais que eles sustentam, as estruturas elementares de parentesco, a metáfora do pai como princípio da separação, a divisão sempre reaberta no sujeito em sua alienação primária, apenas desse lado, e por estas vias que acabamos de citar, devem instaurar- se a ordem e a norma que dizem ao sujeito o que ele deve fazer como homem ou mulher" (LACAN, 1966/1998, p. 863).
} 
cíclico" que continua a ressoar no ditirambo literário através da dimensão dos gritos que o assombra. O ditirambo literário - e depois a tragédia - se construirão sob o recalcamento desta explosão vocal que continuará a assombrá-la, reaparecendo regularmente. Isso mostra claramente que se a tragédia, tem em seus temas, na maioria das vezes, "nada a ver com Dionísio", os gritos, os lamentos, as interjeições que a estrutura, indicam suficientemente suas origens dionisíacas" (VIVÈS, 2019, p. 48, nossa tradução).

Seja qual for a natureza da passagem do dithýrambos para a tragédia, observamos com Vivès (2019) que a existência da tragédia enquanto forma literária só se tornou possível na medida em que o lirismo vocal (phonê) e a fúria dos corpos (mudança dos metros) foram sacrificados sob o altar da palavra (logos). Abandonando a improvisação para aceder à dignidade de gênero literário, o dithýrambos se fez tragoidía, recalcando a dimensão dionisíaca de suas origens. No entanto, observamos que o espectro musical dessa dimensão não deixará de assombrar a tragédia, compondo alguns dos principais elementos que a constituem.

A fala na tragédia era executada sob três modos: recitação, entoação e canto. A essa divisão tripartite somava-se a divisão binária entre performance com ou sem acompanhamento musical. Quando a performance é marcada pelo acompanhamento, este é realizado pelo aulo. Diferente do som da lira - instrumento utilizado nos rituais apolíneos - o som do aulo é agudo e estridente, lembrando gritos e choros, ao mesmo tempo em que suscita sentimentos diversos como tristeza, angústia e às vezes até alegria. Parecido com um oboé, porém com um tubo duplo, o aulo permite ao músico tocar simultaneamente uma melodia e uma base. O resultado é um som bastante versátil que, por intermédio de um timbre muito agudo, coloca em cena a tensão entre as múltiplas figuras da alteridade representadas por Dionísio.

Para demarcar a densidade sonora, temos divisões claras na estrutura do espetáculo, bem como na distribuição de seções com metros especializados. No que diz respeito à estrutura, Romilly (1970) observa que a tragédia grega apresentava habitualmente um prólogo chamado párodo, a entrada do coro. Posteriormente, apresentavam-se os episódios, que podiam variar de dois a cinco, conforme cada caso. Em seguida tínhamos o estásimo, partes da tragédia delimitadas por dois cantos do coro. Ao final, tínhamos o kommós (no qual nos deteremos a seguir) e a saída do coro, denominada exodos.

Nosso interesse aqui está justamente no Kommós, única parte da peça em que o herói canta ao invés de falar ou dizer o texto. Aliás, é importante ressaltar que o herói trágico, em seu momento de maior desespero, de maior desamparo, canta. Esse canto de lamento dialogado chamado Kommós, no qual atores e coristas, juntos, apresentam um ritual ficcional que expressa a dor de uma perda, permite ao herói revelar seu destino e sua dor.

Na discussão sobre os objetos pulsionais (voz, olhar, cíbalo e seio), a voz se apresenta como aquele objeto que suporta o desejo do Outro. Na origem da palavra desiderare, Lacan (1965- 1966/STAFERLA) aponta que o desejo do sujeito se funda no desejo do Outro manifestando- se como tal no nível da voz. Tornando-a não apenas um objeto causal, mas sim o instrumento no qual o desejo do Outro se expressa, a voz é o que sustenta a "passagem" de um significante para o outro, constituindo o essencial daquilo que chamamos de cadeia significante. É nesse nível que emerge, segundo Lacan (1958/1999), aquilo que corresponde ao fato de o significante ser algo que atesta uma presença passada:

o que mais uma vez constatamos aí é que, apesar de existir um texto, apesar do significante se inscrever entre outros significantes, o que resta após o apagamento é o lugar onde se apagou, e é também esse lugar que sustenta a transmissão. A transmissão é algo de essencial nisso, ja que é 
graças a ela que o que acontece na passagem (passagem de um significante a outro) ganha consistência de voz. (LACAN, 1957-1958/1999, p. 355, grifo nosso)

A voz do infans expressada por seu grito é tida como objeto primeiro e, consequentemente, como objeto perdido, pois a partir do momento em que a mãe transforma esse grito em voz, ela (a voz) se torna um objeto perdido por trás daquilo que ela significa para o Outro. Do mesmo modo, a "música sem lira" presente na tragédia faz com que o hino apolíneo se perca em meio ao grito de dor que irrompe afetando o espectador. O ápice desse modo de afetação se dava durante o chamado kommós, um importante momento da tragédia, no qual atores e coristas se engajavam em uma mesma corrente de emoção, dando à tragédia sua singularidade.

\section{O KOMMÓS E A VOZ ENLUTADA NA TRAGÉDIA GREGA}

Segundo Romilly (1970), o kommós constitui-se como um canto de lamento dialogado no qual atores e coristas, juntos, apresentavam um ritual ficcional que expressava a dor de uma perda. Sua virtude está tanto no que diz respeito ao enredo que ele comporta quanto a sua teatralidade. Trata-se, de maneira geral, de um canto de lamentação dos personagens que foram atingidos por determinado destino, levando-os a compor a própria cena como uma espécie de rito fúnebre.

A palavra kommós vem de kompto, que em português significa "bater". Segundo Florence Dupont (2015), esta é uma referência ao gestual dos atores e do coro que, durante o Kommós, golpeiam o próprio peito ou a própria cabeça (gesto característico dos ritos fúnebres). Aliás, opondo-se aos gemidos (gooi), o termo sublinha uma dimensão ritual muito particular que, segundo Alexiou (2002), tem origem nos rituais asiáticos de lamentos antifônicos.

Concordamos com Capponi (2008) que afirma que o kommós se apresenta como o inverso do thrênos, que corresponde a uma realidade na vida cotidiana dos Gregos. Segundo o autor, o termo thrênos tende a se identificar com a palavra goos (gemido, lamento individual) na tragédia grega, o que frequentemente leva a confundi-lo com o kommós. Garvie (1983) resolve essa confusão a partir de um princípio da teatralidade, no qual o autor utiliza formas rituais familiares ao público, ao mesmo tempo em que as adapta para aquela peça em questão.

A transição para o kommós é muito bem marcada. Segundo Dupont (2015), vemos o coro romper a simetria do texto expressando-se em um ritmo iâmbico, contrastando com os rítmicos líricos. Por ser um canto perturbador de dor, ele é frequentemente apresentado sobre o modo lídio, o qual permite a exploração dos paroxismos do pathos. Segundo Capponi (2008), a grande recorrência de termos autorreferenciais, como nesse caso, garante a realização do rito que ali está em andamento. $\mathrm{O}$ autor ainda lembra que os atos verbais realizados no palco são designados como ações que cumprem uma ordem de realidade que é, ao mesmo tempo, dos personagens e do público. Sendo assim, um rito ficcional é criado no instante da performance como resultado de uma modelagem estéticomusical.

O rito criado em cena no kommós faz a linguagem tomar o lugar do gesto. Segundo Capponi (2008, p. 135):

\footnotetext{
"As palavras imitam o barulho dos golpes, sem dúvida: a abundância de explosivos nos termos apriktoplêkta polupalakta acrescentada à rima interna, cria um efeito mimético. Assim, as palavras permitem a realização deste ritual que faltou, realizando-se precisamente porque as palavras dizem que o faz" (tradução nossa).
} 
Logo, o kommós vai se revelando uma forma de lamentação ritmada, acompanhada de gestos repetidos cujo conteúdo é a descrição de uma cena que, de algum modo, está relacionada com determinado passado. Apesar disso, seu conteúdo diz respeito ao mythos e não à história, uma vez que não se trata apenas da narrativa dos fatos materiais, mas sim da construção de uma narrativa simbólica inserida numa lógica de rememoração e reparação.

Constatamos, com Capponi (2008), três tempos do kommós: paroxismo da lamentação, considerações conclusivas e termos autorreferenciais, sendo estes últimos empregados em favor da produção do canto e do ritual, redefinindo o kommós enquanto objeto poético: "Oposta à infelicidade (paramousos), literalmente: que vai contra as Musas - e engloba ao mesmo tempo as duas dimensões deste conjunto: ficção ritual e composição artística. Além disso, a parte lírica termina com essas palavras" (2008, p. 139, tradução nossa).

Segundo Capponi, os termos autorreferenciais que aparecem ao longo do kommós pontuam e determinam o processo: palavras como kateuchê, goos, ara, humnos, paian, thrênos etc, designam unidades de discursos que apresentam eficácia tanto na economia da narrativa, quanto na realização do rito. Nesse sentido, a aproximação entre kommós e thrênos não deve ocultar aquilo que traz sua especificidade: há no kommós os termos que descrevem a ação verbal que está em curso, bem como os sinais do discurso que a revestem.

Como dissemos anteriormente, o kommós é o único momento no qual o herói trágico canta. Jean-Michel Vivès (2003) lembra que Freud associa o herói trágico ao pai arcaico moribundo, e que seu canto seria uma forma sublimada do som de sua agonia, de seu estertor da morte: "Poderíamos igualmente, seguindo essa hipótese, resolver o paradoxo da presença do canto do heróis no instante de desamparo. De fato, o canto só é a modulação do grito. Ele comemora e vela o grito do pai agonizante" (2003, p. 16, tradução nossa).

Em português "velar" tem dois sentidos: "velar" no sentido de cobrir-se com um véu e também "velar" no sentido de permanecer em vigília, como, por exemplo quando se vela um morto. Nota-se, portanto, que o canto enlutado do herói no kommós diz respeito à dor de algo que se perdeu e que precisa, de algum modo, ser velado.

Lacan nos dá um belo exemplo desse duplo movimento de velar-revelar que suscita o efeito da beleza na relação temporal do entre Trata-se da cena em que Antígona, no momento de seu ato, vai para além da fronteira de até - limite que a vida humana não pode transpor por muito tempo:

\footnotetext{
Uma primeira vez nas trevas ela foi recobrir o corpo do irmão com uma camada fina de poeira que o cobre o suficiente para que seja velado à vista. Pois não se pode deixar ostentando na cara do mundo essa podridão onde os cães e os pássaros vêm arrancar retalhos para levá-los, diz-nos o texto, para os altares, no âmago das cidades, onde vão disseminar, ao mesmo tempo, o horror e a epidemia (LACAN, 1959-1960, p. 319- 320).
}

Ao mesmo tempo em que Antígona coloca sob o rosto do irmão um véu de poeira para que a podridão e o horror de seu cadáver não sejam escancarados ao mundo, ela também revela, através desse gesto, a presença do terrível desconhecido que existe no além de até. $\mathrm{O}$ ato de velá-lo e revelá-lo, cobri-lo com a poeira e descobri-lo, faz emergir essa estranha beleza que habita a transição.

A beleza da transição, segundo o próprio Freud (1916), ressalta o valor de raridade e precariedade das coisas. Há uma efemeridade no belo que nos oferece um gosto prévio do luto de seu próprio desaparecimento. Sendo assim, o encontro com ele, com o belo, promove o reencontro de algo perdido em nós para todo o sempre, a saber, aquilo que se 
constitui como o próprio ato de perder. É essa estrutura fundamental que Lacan nomeia "Outra coisa", ou seja, aquilo que no reencontro do objeto é representado por Outra coisa.

A constatação do objeto perdido na ocasião de seu reencontro vela a Coisa ao mesmo tempo em que a revela como Outra coisa. O encontro com a beleza que emerge do caráter de transitoriedade do intervalo entre velar e revelar constrói uma espécie de dique que sustenta, de forma suficiente, aquilo que da experiência foi apresentado como terrível.

A constatação melancólica de que tudo na vida se esvai - e de que nada que fizermos apagará o fato de que "não sairemos vivos desta" - pode ser suplantada pela ilusão do belo. Freud em Além do princípio do prazer (1920) utiliza a expressão "ilusão benévola" (p. 60) para figurar o desejo persistente entre os humanos de acreditar numa pulsão para a perfeição que os protegeria do duplo reconhecimento de que a vida é um curto intervalo no caminho para a morte e da existência da pulsão de morte.

Essa parece ser a posição de Freud em seu comentário de 1916 sobre a transitoriedade. Frente à atitude de desgosto e de revolta de seus dois amigos (Raine Maria Rilke e Lou Andreas-Salomé) que lamentam a efemeridade da vida, Freud opta por uma terceira via: a de ver na beleza do transitório o real valor da experiência que, dado o seu caráter perecedouro, rapidamente se desvanece.

Reapresentar o terrível ao revesti-lo dessa fina camada de poeira chamada "o belo" permite a recoberta do que dele não pode ser deixado à vista, ao mesmo tempo em que faz transparecer aquilo que, do anteriormente conhecido, havia se tornado terrivelmente estranho. A beleza que surge nesse movimento faz do humano uma maravilha-assombrosa (deinós), transforma todo esse assombro em força extraordinária de ultrapassamento, avesso inquietante da paralisação causada pelo temor concentrado.

\section{O "PARA SEMPRE PERDIDO" E A VOZ ENLUTADA}

O lugar que o poeta/compositor da tragédia atribui ao kommós determina todo o resto da peça, incluindo os próprios eventos de sua narrativa. Por quê? Porque ele impõe, em certa medida, a assimilação de unidades discursivas em atos verbais que se sucedem em função de uma certa estratégia narrativa que é a de colocar em cena, o tempo todo, a marca de uma voz enlutada.

Nicole Loraux (1999), em seu belíssimo livro La voix endeuillée (A voz enlutada), nos mostra como o impacto da perda nas palavras alimenta a emoção trágica. A autora apresenta uma série de argumentos de que o entendimento da tragédia grega passa pela escuta daquilo que está inscrito por trás das palavras. O interesse de Loraux por aquilo que se escuta na tragédia sobrepõe- se ao interesse ordinário de outros autores, que apostam no entendimento da tragédia a partir do que nela é visto.

$\mathrm{Na}$ oposição aristotélica lexis / ópsis, a autora parece encontrar na primeira um interessante jeito de reconstruir a língua trágica que, para ela, se expressa principalmente no lamento sem fim sobre a finitude humana. A ilusão da eternidade implícita no tempo dos deuses coloca, aparentemente, o herói trágico sob o signo de uma perda, de um luto que, longe de ser elaborado, produz sofrimento e arraiga conflito.

Segundo Loraux (1999), o conflito está exposto no gênero trágico através das duas acepções rivais da palavra aeí, cuja tradução bastante imperfeita, mas coerente, seria o advérbio "sempre". Recuperando um estudo de Benveniste sobre a noção de aion ("força vital"), a autora nos mostra que a partir de certa época o ser humano elevou a intemporalidade a um estatuto essencialmente temporal. Ela lembra que a convergência 
entre aion e os advérbios deles derivados dá a esses advérbios o significado de "sempre", demonstrando que:

Esse "sempre" indica o que é perpetuamente recomeçado, antes de ser um "sempre" permanente e imóvel (...). Transitório e permanente, se exaurindo e renascendo no curso das gerações, abolindo-se em sua renovação e permanecendo para sempre por sua finitude sempre reiniciada, (...) a força de vida implica recriação incessante do princípio que a alimenta, sugerindo ao pensamento a imagem mais instantânea daquilo que se mantém sem fim, no frescor do sempre novo (BENVENISTE apud LORAUX, 1999, p. 47-48, tradução nossa).

Nesse sentido, é possível observar, junto com Loraux, algumas ocorrências políticas do aeí em relação ao aspecto autóctone dos gregos: Thucydide dizia que eram os mesmos homens que sempre (aei) habitavam a Ática (o "sempre" aqui tem o sentido de 'geração após geração'); Péricles refere que o país é habitado sempre (aiei) pelos mesmos, através da sucessão das gerações. Também é possível encontrar o uso político do aei em relação ao tema da perpetualidade daqueles que ocupam o poder.

Temos, por exemplo, o uso dessa palavra em reflexões acerca da arché (elemento que deveria estar presente em todos os momentos da existência de todas as coisas do mundo), que, de certo modo, implica o sentido de uma repetição constituída em uma continuidade sem ruptura. Ou ainda, o uso performativo do aei no contexto das reflexões em torno dos arcontes, que eram os títulos hereditários e vitalícios dos membros de uma assembleia de nobres da Atenas Antiga. Através deles, a cidade se perpetuaria de forma sempre idêntica, constituindo precisamente a definição mais atual de política, no que diz respeito a sua eficácia, ou seja, naquilo que ela dá como modelo à cidade em relação à regularidade repetitiva e natural da sucessão das gerações.

A força vital dos descendentes de Éaco, entre os quais estão inscritos Aquiles e Ajax, se propaga em um "sempre"; os velhos que sempre honram o poder do trono de Laios; as transmissões das desgraças de geração em geração. Todos estes são exemplos do emprego do advérbio aei que, aos poucos, vai assumindo o estatuto de um "sem cessar". Contudo, Loraux observa que a ocorrência política do aeí ainda se apresenta em menor escala quando comparada a outros fins do advérbio no gênero trágico, e ressalta que não é aos humanos que o "sempre" está referido na tragédia, mas sim ao "tempotodo-poderoso".

Há um limite impensável entre o tempo dos deuses e o tempo dos homens, impedindo-os de se articularem. O problema humano com o "sempre" se evidenciará na frequente fixação do herói trágico em determinado sofrimento que não cessa - traço inquietante de uma paixão latente e mal dominada. Loraux afirma que, de todos os trágicos, é Sófocles que mais explicita tal fixação no centro de sua obra, de modo que a loucura de seus heróis sempre está associada à crença de que as coisas humanas são regidas pelo aeí. Ajax, Antígona, Electra, Édipo, Filoctete, são todos personagens de Sófocles marcados por uma fixação, digamos trágica, no "sempre".

Ajax em sua paixão irrefreada por obter a qualquer custo as armas de Aquiles; Antígona e o dilema de seu desejo que se eterniza em sua própria morte em detrimento da morte simbólica de seu irmão; Electra que está para sempre em luto por seu pai, o que incita consequentemente uma vingança associada ao aeí; Édipo como fillho da condenação perpétua de seu pai; Filoctete marcado por seu desejo irrefreável de contribuir na guerra de Tróia, não hesita em assentir ao pedido de ajuda daqueles que o deixaram para morrer.

As reflexões em torno da temporalidade sem tempo do aeí em tais personagens só podem estar completas se introduzirmos na discussão a forma como tal advérbio é enunciado nas narrativas trágicas. Essa é para nós a grande contribuição de Nicole 
Loraux, que percebe, de maneira sensível, algo que nos é esclarecedor: há no aeí desesperado, esse "para sempre" perdido da experiência humana (e que, portanto, é indício de uma perda que remete a um luto), que retorna nas tragédias como um som específico. Trata-se da interjeição aiâ̂, vocalise pelo qual a dor é expressa sem mediação da língua articulada.

Segundo Loraux (1999), o advérbio aeí parece encontrar um dublê na interjeição aiâ̂, esta última funcionando como uma espécie de queixa nua de um luto transformado em pura emissão vocal. Comparado a uma lamentação (thrênos), o aiaî evidencia o relutante vínculo entre o pranteador e seu choro, de modo a tornar-se a ligadura fônica do sofrimento com o sofredor. Nesse ponto, que o aiẩ é a interjeição lamentosa e sem sentido, na qual o som coloca em primazia a significação que jorra do herói quando este é confrontado pelo trágico:

Entre aeí e aiâ̂, não há outro parentesco que não seja a contiguidade - contiguidade contextual, na expressão de uma dor que se eterniza e se alimenta de si mesma; contiguidade sonora, igualmente, sendo que aei pode também tomar a forma aieí pela qual o advérbio se aproxima foneticamente da interjeição. E de fato, numerosas são as evocações do luto onde aeí parece chamar aiaî (LORAUX, 1999, p. 59, tradução nossa).

Vejamos alguns exemplos. Em Electra de Sófocles, após ter evocado o rouxinol desolado sob o modo de aién, do "sempre", Electra lamenta a Niobé:

Insensato é aquele que se esquece. De um pai morto por forma lastimável. A mim, porém, ao meu coração é cara aquela que chorosa. Ítis, Ítis lamenta sem cessar, a ave de dor enlouquecida, de Zeus mensageira. Ai Nióbe, de amarguras a rainha, eu te considero divina, a ti, que em seu túmulo de pedra. Choras aiâ̂ (sem cessar). Em Édipo em Colono, Ismênia se lamenta sobre sua sorte após a morte de Édipo: Aiâ̂! Infeliz de mim! Como sozinha e sem recursos assim. levarei minha vida infausta?

Na tragédia Helena de Eurípedes, o coro lamenta o destino doloroso da mulher que dá seu nome à peça:

Aiâ̂! É muito penosa divindade o teu destino, mulher! Uma vida que não é vida tomou, tomou a ti, quando Zeus da mãe te gerou.

Ajax (Aías), cujo nome próprio já evoca a sonoridade desse som do desespero, descobre o lamento aiaî em diálogo com Tecmessa. Esta, ao pronunciar o nome de Ajax no mesmo diálogo em que o herói descobre o desespero, também faz alusão ao lamento implícito em seu nome:

TECMESSA: Não soberano Aías (Ajax), suplico-te, não digas isso! AJAX:Não estás fora? Não conduzes de volta teus passos? Aiâ̂, aiaî!!

Teríamos inúmeros exemplos para demonstrar a importância e a presença do aiâ na tragédia grega. Apresentando-se sempre nesse jogo de duas vogais, "a" e "i", bem como nas combinações que delas são possíveis (ai, ia, aia, iaiá), o aiaî é, segundo Loraux (1999), o lamento dos lamentos materializado em uma emissão vocal genérica, condensando nela todo o registro expressivo da dor.

O campo da Fonética e da Fonologia, por exemplo, ensinam que na produção dos segmentos vocálicos há a inexistência de obstrução do trato vocal. Não há na produção dessas vogais fricção das pregas vocais. O som é vozeado ou sonoro. O [a] é uma produção sonora baixa, central e arredondada, ao passo que o [i] é alta, anterior e arredondada. Essa descrição mostra que a produção da voz se manifesta como ato de 
articulação no corpo (sobretudo na produção de ligadura fônicas das vogais) que apontam para a irrupção do grito do bode sacrificado que, transformado em canto no kommós, faz memória ao "para sempre" perdido da experiência humana.

\section{CONSIDERAÇÕES FINAIS}

Há na tragédia grega a inscrição de uma voz enlutada, observamos que essa voz enlutada aponta para a experiência do "para sempre perdido" - experiência na qual apalavra não toca. Trata-se do chamado pedaço de Real que padece de mediação do significante (LACAN, 1959- 60/1991, p.157). Tomada por nós como rastro de um grito que deixou de ser grito, a experiência para sempre perdida expressada na tragédia através do â̂â, recupera certa dimensão do laço mais primitivo entre o sujeito e o Outro.

Tal laço primitivo nos remonta à vivência de satisfação e seus efeitos. A ideia mítica de uma primeira mamada que injeta a falta na vida do bebê, ao mesmo tempo em que cria o desejo de um retorno a essa primeira satisfação, seria o grande evento que produz uma perda capaz de fazer brotar o sujeito do desejo. É desta perda que estamos eternamente enlutados.

Cada parte da tragédia combina modos de articulação que correspondem a diferentes modos de dizer que se referem à enunciação de uma perda, da falta. Ficou claro para nós que, na tragédia, se trata da voz enlutada que, escrita sob o dizer aeí, é enunciada pelo dito aíaí. O grito do bode sacrificado remonta ao grito do infans cuja vibração sonora tenta não romper o silêncio, ao mesmo tempo em que se faz ouvir. $\mathrm{O}$ grito como ato de evocação, necessita de um vazio para ser expresso - vazio que possibilite ao sujeito ser atravessado por um espaço de silêncio sem deixar que este o habite.

Se o vazio é associado à Coisa que em nós está para sempre perdida, Lacan colocará essa Coisa (das Ding) no lugar central do vazio, nomeando esse local "exterioridade íntima" ou "extimidade" (LACAN, 1959-60/1991, p. 173). Assim, o mais íntimo do sujeito, estaria fora dele, e sua busca estaria voltada para o reencontro desse "Outro absoluto do sujeito" (LACAN, 1959-60/1991, p.70).

Ao falar do ponto vazio do sujeito, Lacan situa o objeto causa de desejo como seu operador, localizando-o em um ponto êxtimo, mantendo as aproximações entre das Ding e o objeto $a$. Será por causa de das Ding que a experiência com o objeto será sempre faltante. Sendo assim, a presença da voz enlutada na tragédia grega parece fazer memória àquilo que se estrutura a partir de um luto primordial, um luto essencial, que se materializa na forma de uma ligadura fônica sustentada na vogal.

\section{$\overline{\text { REFERÊNCIAS }}$}

ARISTÓTELES. Poética. Edição bilíngue. Introdução, tradução e notas de Paulo Pinheiro. Rio de Janeiro: Editora 34, 2015.

ALEXIOU, M. The Ritual Lament in Greek Tradition. New York: Rowman \& Littlefield, 2002.

CAPPONI, M. La parole comme geste. La conception antique de la parole efficace et ses implications dans le théâtre tragique. Tese. (Doutorado em Letras). Universidade de Neuchâtel, 2008. Disponível em https://core.ac.uk/download/pdf/20643362.pdf Acessado em julho de 2019.

DUPONT, F. Les Monstres de Sénèque. Pour une dramaturgie de la tragédie romaine. Paris: Belin, 1995.

FREUD, S. (1905) Três ensaios sobre a teoria da sexualidade. In: Edição Standard Brasileira das Obras Psicológicas Completas de Sigmund Freud. Tradução J. Salomão (Vol 7.) Rio de Janeiro: Imago, 1976.

FREUD, S. (1916). Sobre a transitoriedade. In: Edição Standard Brasileira das Obras Psicológicas Completas de Sigmund Freud. Tradução J. Salomão (Vol. 14). Rio de Janeiro: Imago, 1996.

FREUD, S. (1917[1915]) Luto e Melancolia. Tradução de Marilene Carone. São Paulo: Cosac Naify, 2011. 
FREUD, S. (1920) Além do Princípio de Prazer. In: Obras Psicológicas de Sigmund Freud. Trad. Luiz Alberto Hanns. São Paulo: Imago, 2006. v. II. p. 123-199.

GARCIA-ROZA, L. A. Freud e o inconsciente. 24.ed. - Rio de Janeiro: Jorge Zahar Ed., 2009. JEANMAIRE, H. Dionysos, Histoire du Culte de Bacchus. Paris: Payot, 1970.

LACAN, J. (1957-1958). O seminário, livro 5: As formações do inconsciente. Tradução de Vera Ribeiro. Rio de Janeiro: Jorge Zahar, 1999.

LACAN, J. (1959-1960). O seminário, livro 7: A ética da psicanálise. Tradução de Antônio Quinet. Rio de Janeiro: Jorge Zahar, 1991.

LACAN, J. (1965-1966). Le Séminaire, Livre 13: L'objet de la psychanalyse. Versão STAFERLA. In. http://staferla.free.fr/S13/S13\%20L'OBJET.pdf. Acesso em 09 de agosto de 2019.

LORAUX, N. La Voix endeuillée. Essai sur la tragédie grecque. Paris: Gallimard, 1999.

PERES, U. T. (1996). "Dúvida melancólica, dívida melancólica, vida melancólica”. In: Melancolia. Urania Tourinho Peres (org). São Paulo: Escuta.

REIS, M. L. O. Da experiência de perda à perda de experiência: um estudo sobre a Erfahrung na teoria psicanalítica, na filosofia e na clínica. 2015. Tese (Doutorado em Psicologia Clínica) - Instituto de Psicologia. São Paulo.

ROMILLY, J. (1970). A tragédia grega. Tradução de Ivo Martinazzo. Brasília: UnB, 1998. SAFATLE, V. A paixão do negativo: Lacan e a dialética. São Paulo: Unesp. 2006

VIVÈS, J.-M. La voix, objet de la pulsion aurale. Revue la lettre de l'enfance et de l'adolescence, n. 52, 2003.

VIVÈS, J.-M. La catharsis, d'Aristote à Lacan en passant par Freud. Une approche théâtrale des enjeux éthiques de la psychanalyse. Recherches en psychanalyse, $\mathrm{n}^{\circ}$ 9, p. 22-35, 2010.

VIVÈS, J.-M. A voz na clínica psicanalítica. Tradução de Vera Ribeiro. Rio de Janeiro: Contra Capa, 2012.

VIVÈS, J.-M. La médiation par le théâtre: Freud et Dionysos sur la "scène" thérapeutique. Les éditions Arkhê, 2019.

Recebido: 3/4/2021

Aceito: 27/9/2021

Publicado: 24/11/2021 